\title{
Learners' Errors and their Evaluation
}

\author{
Laxmi Bahadur Maharjan
}

\begin{abstract}
This study identifies, describes and evaluates the learners' errors, and determines the gravity of those errors in terms of intelligibility and acceptability by the Nepali, non-Nepali and native English speaking teachers. This study was targeted at the grammatical errors and perceptions of different English teachers on those errors. The research findings were analyzed and expressed quantitatively. The study revealed that the Nepali English teacher evaluators were found to be the most severe judges. The nonNepali (i.e. other than Nepali and the native English) evaluators were in between the Nepali and the native English evaluators. The researcher proposes to treat the most serious errors for Nepali and nonNepali English teachers with priority.
\end{abstract}

Key words: error analysis, grammatical errors, error gravity

\section{Introduction}

Nepali is the national language for the Nepalese and it is used all over Nepal for official and ordinary communicative purposes. In this sense, English has nothing to do with internal communication in this country. It is taught as a foreign language in Nepal. However, it has been given a significant place in the Nepalese schools, higher secondary and college level curriculums. Thus, the students study English for academic purpose here. The concern of the present study is with the Nepalese students' language and its evaluation by teachers of English.

An error as produced by the second language learners has been the central concern of every applied linguist. A concern has also seen on how non-native English teachers judge errors for their seriousness, but the linguists are examining whether nonnative teachers have correctly been able to identify what erroneous is and what is not, or explain why something is erroneous. With this concept in mind, the present study has focused on evaluating the students' errors, and looked at whether the teachers bring improvement in their ways of evaluating their students' languages as proper or not. This study emphasised on the grammatical errors the higher secondary school level students in Nepal committed in written English, and how the English teachers, both non-native teachers (including Nepali and non-Nepali) and native English speaking teachers, reacted to such errors in terms of their seriousness.

\section{Objectives of the study}

The major objectives of this study were to identify, describe and explain the grammatical errors committed by the Nepali learners of English; to evaluate the errors by the Nepali, non-Nepali English teachers and native English speaking teachers; to find out whether there are any consistent and significant differences in the error gravity perceptions of the Nepali, non-Nepali and native English speaking teachers; to determine the gravity of the errors and their hierarchy through 
the lens of intelligibility and acceptability against the background of the evaluators; and to suggest pedagogical implications on the basis of the findings of the present research.

\section{Significance of the study}

So far, the previous studies were concerned with the perception of errors by NS and NNS teachers, nonteacher NSs, and non-teacher NNSs (henceforth we shall use native speaker as NS, non-native speaker as NSS, native speakers who are non-teachers as non-teacher NSs, and non-teacher NNSs as nonnative speakers who are non-teachers). All these studies, however, focused on the teacher or the non-teacher, and that the non-native speakers of English were the chief source of data for their studies. Unlike all the studies carried out so far, the present study concerned with the comparative study of the perception of the English language errors by the NS and NNS teachers, and with a view to find out whether there were any perceptual differences between NNS teachers themselves- that is to say between Nepali English teachers and non-Nepali English teachers. This is the chief difference of the present study which has never ever been carried out before. This study has examined the faculty responses to the grammatical errors of the students who are non-native speakers of English. The author hopes that the teachers of both native and nonnative (including Nepali and non-Nepali) speakers of the target language may differ considerably in their evaluations of learners' errors. However, a consensus will be sought for so as to bring a change in the modality of evaluation practices.

\section{Viewpoints on error perceptions}

Teachers seem to focus on the English language errors today. Of course, there is no consensus on errors among the teachers themselves; many teachers may be unaware of the relative merits of these evaluation practices, nor have they received specific training in error evaluation. This knowledge gap brought different judges assess the perception of different kinds of errors differently.

There are different viewpoints on the perceptions of errors. As regards to the rating of the errors, James (1977) claims that non-native judges tend to mark more severely than native speakers do. Ervin (1979) concludes that the Russian NS teachers are more severe in their judgments of errors than the American NNS teachers. Hughes and Lascaratous (1982) conclude that the NSs, particularly the nonteachers, judge errors much more leniently than the NNSs. Davies (1983) insists that native speakers are more lenient than non-native speakers. Sheorey (1986) reveals that NSs are much more tolerant of errors. They deducted fewer points than nonnative teachers in evaluating the same erroneous sentences. But more important, the study gives an indication, of which errors are most irritating to native English teachers. Santos (1988) concludes that the NNS professors are more severe in their judgment than the NS professors. Kobayashi (1992) views that the NSs are stricter in their judgments of grammaticality than the NNSs. Schmitt (1993) admits that non-native teachers are harsher on errors than native speakers. McCretton and Rider (1993) report that the NNSs are consistently more severe in their judgments. Awasthi (1995) concludes that the native English speaker teachers are more lenient compared with their non-native counterparts and that the former judges are found to make a finer distinction while evaluating the errors. And Flatley (1997) concludes that NNS teachers emerged as more tolerant of errors, both in theory and in practice, than their NS counterparts.

The above literature, however, shows the two contrasting viewpoints. Unlike many others, Ervin (1979), Kobayashi (1992) \& Flatley (1997) are at variance. They view that the NSs are stricter in their judgments of the learner errors.

The present study has the main theme to reach at the perception of teachers on errors. Of course, most of the above studies highlighted the native speakers' leniency over the errors. However, it is hoped that the findings of the present study will help positively to change the attitude of English language teachers of their learners' errors in such a way that they may be more tolerable of errors in English. 


\section{Research method}

This quantitative study was carried out in two phases. In phase one, analysis of errors, the researcher collected the answer sheets of the students of the higher secondary school level students (See appendix I for test items given to students), and then identified the errors committed on grammatical categories such as articles, prepositions, modal verbs, conjunctions, conditionals, to infinitives and gerunds, relative pronouns, question tags, $S$-V agreement, reported speech, negativization, clauses, interrogation, tense and passivization. The errors were described accordingly. In this phase, he included all the students of grade twelve studying throughout Nepal as the major population in his study. The selected students represented all the five development regions, i.e. the eastern region, the central region, the western region, the mid-western region and the far western region. Care was also taken that all the ecological belts such as the Terai, the Hill and the Mountain included in the study.

The second phase of the study contained three sorts of evaluators - 100 native English speaking teachers, 100 Nepali English teachers teaching in the higher secondary schools in the country, and 20 nonNepali English teachers teaching elsewhere from the countries other than Nepal, and England, America, Australia, the New Zealand and Canada. This second phase which is the main part of the research deals with the analysis of the perceptions of the evaluators on students' errors.

The researcher used the stratified random sampling procedure in order to select the population for this study. For this purpose, he selected 100 Nepali English teachers from the total respondents purposively. As regards to the native English speaking teachers and non-Nepali English teachers, he contacted them globally through e-mail correspondence. Questionnaires were mailed to 300 English teachers of different private and public schools, colleges and universities worldwide. The mailed directions gave participants the option of completing the survey either on paper to submit through postage or on on-line through e-mail.
Earlier, a questionnaire was developed to measure the perceptions of the evaluators; the questionnaire containing 100 erroneous sentences on the major grammatical categories was developed on the basis of a five-point Likert attitude scale (See appendix II for the types of questions asked).

There were a total of 140 useable surveys submitted electronically through e-mail and postage as well for a response rate of $46.66 \%$, which is a good response rate for a mail survey. I, then, selected 100 responses received from native English speaking teachers, and 20 non-Nepali English teachers working in different parts of the world other than Nepal- however 20 responses were removed which gave a final response rate of $40 \%$.

\section{Data analysis}

The analysis of data comprises discussion of respondents' errors and the situation of error gravity. The respondents' errors part concerns with interpretation of the elicited English language errors on 15 major grammatical categories, showing the difficulty level, their error frequency and analysis of the possible causes of the errors committed as well.

Keeping the sensitivity of the grammatical errors in mind, an analysis of the errors obtained both from multiple choice questions and written compositions has also been made. Since the nature of works of multiple choice tests and written composition tests are different, the errors resulted from these tests have produced different results. This is shown in the table 1 (see next page).

Multiple choices and the written compositions are different tests types. These tests in the table above have resulted with no any similar pattern of percentage of errors. The percentage of errors such as in the category prepositions ranks the $9^{\text {th }}$ in multiple choice tests, but it ranks the $2^{\text {nd }}$ in the written composition test. This is an expected difference which occupies a significant position in the present study.

It is, however, found that the same grammatical category did not provide identical results, and thus different hierarchies are established. 
Table I: Different Nature Questions Yielding Different Percentage and Ranks in Errors

\begin{tabular}{|c|c|c|c|c|c|}
\hline S.N. & Grammatical Categories & $\begin{array}{l}\text { Error from } \\
* \text { MC tests }\end{array}$ & Hierarchy & $\begin{array}{c}\text { Error from } \\
* W C \text { test }\end{array}$ & Hierarchy \\
\hline 1. & Prepositions & $43.02 \%$ & $\mathrm{IX}$ & $20.05 \%$ & II \\
\hline 2. & Articles & $55.21 \%$ & 1 & $16.51 \%$ & III \\
\hline 3. & Tense & $47.18 \%$ & III & $25.16 \%$ & 1 \\
\hline 4. & Relative clauses & $42.86 \%$ & $x$ & $3.93 \%$ & VIII \\
\hline 5. & S-V agreement & $52.62 \%$ & II & $5.50 \%$ & $\mathrm{VI}$ \\
\hline 6. & Passivisation & $43.36 \%$ & VII & $6.29 \%$ & $\mathrm{~V}(\mathrm{i})$ \\
\hline 7. & Interrogation & $45.34 \%$ & $\mathrm{~V}$ & $4.32 \%$ & VII \\
\hline 8. & To inf/gerund forms & $43.04 \%$ & VIII & $7.08 \%$ & IV \\
\hline 9. & Conditionals & $45.20 \%$ & VI & $3.54 \%$ & IX \\
\hline 10. & Modal verbs & $45.56 \%$ & IV & $6.29 \%$ & $\mathrm{~V}$ (ii) \\
\hline 11. & Multiple errors & --- & & $1.34 \%$ & $x$ \\
\hline
\end{tabular}

* MC test and WC test stand for Multiple Choice Test and Written Composition Test.

Hierarchy for multiple choice tests: 'articles > $\mathrm{S}-\mathrm{V}$ agreement $>$ tense $>$ modal verbs $>$ interrogation $>$ conditionals $>$ passivisation $>$ to infinitives/gerund forms $>$ prepositions $>$ relative clauses'

Hierarchy for written composition test: 'tense $>$ prepositions $>$ articles $>$ to infinitives/gerund forms $>$ passivisation $>$ modal verbs $>$ interrogation $>$ relative clauses $>$ conditionals $>$ multiple errors'

Likewise, the analysis of data also deals with the situation of error gravity which concerns with establishment of hierarchy of errors and exploration of statistical findings regarding the perceptions of different teacher evaluators, and it thus aims to find out if there are any consistent findings of this study with the earlier studies made so far on error perceptions.

The study, however, started with the collection of numerical data on a subject followed by a statistical analysis elsewhere: statistical package, SPSS, was used for numerical analysis.

\section{Findings}

The major findings drawn from the analysis of the data include:

\section{Grammatical errors and their frequency}

The errors committed at the major grammatical categories are given on the basis of their frequency.

Tense holds the highest level of difficulty for the students, where they have committed errors at
25.16\%. Errors in prepositions rank the second highest grammatical category in terms of the frequency of errors, the percentage being 20.05\%. Likewise, errors in articles are committed by $16.5 \%$, and this holds the third highest rank in terms of the frequency of errors. It is found that ninety errors (7.08\%) are found in the use of to infinitives and gerund forms. In terms of the frequency of errors, the errors in 'to infinitives and gerund forms' rank the $4^{\text {th }}$ position in the error category. Similarly, eighty errors each have been committed in the error categories like passivization and modal verbs. They rank the $5^{\text {th }}$ position comprising $6.29 \%$ of the total errors committed by the students. In the same way, seventy errors $(5.50 \%)$ have been found in the use of concord between different elements in a sentence (S-V agreement), and fifty five errors that comprise $4.32 \%$ have been recorded in interrogation. The relative clauses category ranks the $9^{\text {th }}$ order in terms of the level of error frequency, and this constitutes the $3.93 \%$ errors out of the total. Likewise, forty five errors (3.54\%) have been found in conditionals. Moreover, the ones committed at multiple categories which consist of the errors committed in the grammatical categories such as negativization, conjunctions, relative pronouns, tag questions, and reported speech comprise $1.34 \%$ errors.

\section{Teachers' perceptions on students' errors}

The results revealed that in terms of acceptability judgment, the Nepali English teachers were found to be the most severe judges against their native 
English speaking teachers who leniently marked the errors. The non-Nepali evaluators were in between the two, whereas in terms of intelligibility judgment, the native English evaluators were far more lenient than either Nepali or non-Nepali English teachers. The Nepali and non-Nepali teacher evaluators did not differ significantly, but when compared with the native English evaluators individually, they were significantly and statistically more serious while they evaluated the learner errors.

The Nepali teachers deducted $7.51 \%$ and $2.84 \%$ points more respectively than the native English and non-Nepali evaluators in acceptability judgment, which increases to $14.1 \%$ and $10.02 \%$ in intelligibility judgment.

This, (except the non-Nepali teachers), confirms the findings of James (1977), Hughes and Lascaratou (1982), Sheorey (1986), Awasthi (1995) who concluded that native speakers (teachers as well as non-teachers) appear to be more tolerant of errors made by ESL students than the non-native speakers are.

\section{Error perception in terms of gender}

Native English Female evaluators (68.56\%/54.13\%) were more severe than their male counterparts $(66.96 \% / 50.64 \%)$ in both acceptability and intelligibility judgments. This shows that the native females' deduction of scores is by $1.60 \%$ in acceptability and by $3.49 \%$ more in intelligibility judgments than their male counterparts.

The Nepali male (76.07\%) and female (76.82\%) evaluators showed a consistent rating in the acceptability judgment. This data indicate that the Nepali male and female evaluators have executed a finer judgment in the acceptability field, but in the intelligibility judgment, the male evaluators are ahead by $4.95 \%$ : they have accorded little more seriousness to the grammatical errors.

Non-Nepali male evaluators were more serious in both acceptability and intelligibility judgments. The male evaluators were ahead of their female counterparts by $2.03 \%$ in acceptability judgment and by $11.39 \%$ in intelligibility judgment.

\section{Error perception in terms of age, qualification and training}

The older native English (71.36 \%/ 64.29\%) and Nepali (75.49\%/80.51\%) evaluators were more serious in acceptability judgment in comparison to their younger evaluator counterparts by $7.07 \%$ and $5.02 \%$ respectively. In case of non-Nepali evaluators, the younger ones $(73.93 \%$ / 72.24\%) were slightly ahead of their older counterparts. As regards to the intelligibility judgment, the different evaluators have had different readings on grammatical errors. In case of Nepali, the younger evaluators $(67.21 \%$ / 64.28\%) were more serious. Similarly, in case of the non-Nepali evaluators, it is the older evaluators who were more serious $(68.20 \%$ / 62.11\%) in the intelligibility judgment, but as regards to the native English evaluators, both younger and older evaluators were consistent (52.62\% and 52.58\%) in the intelligibility judgment.

As regards to qualification, all the post-graduate evaluators were more severe in both acceptability and intelligibility judgments. The native English post-graduate evaluators were ahead by $6.52 \%$ in acceptability and $2.87 \%$ in intelligibility judgments, the Nepali English evaluators by $16.98 \%$ and $3.42 \%$, and the non-Nepali evaluators ahead by $4.18 \%$ in acceptability and by $5.40 \%$ in intelligibility judgments.

Both trained and untrained native and Nepali English evaluators consistently evaluated the errors in both acceptability and intelligibility judgments. There was a differential note of only $0.85 \%$ in acceptability and $0.54 \%$ in intelligibility judgments shown by native English evaluators. Likewise, the Nepali evaluators showed a differential note of only $0.09 \%$ in acceptability and $0.41 \%$ in intelligibility judgments. Unlike the above, the untrained nonNepali evaluators showed their severity by $6.93 \%$ in acceptability and by $14.94 \%$ in intelligibility judgments than by their trained evaluator counterparts. Despite how severe the trained and untrained native, Nepali and non-Nepali English evaluators are, except the non-Nepali ones, the trained and untrained native and Nepali English evaluators' judgments of the errors are remarkably consistent and noteworthy. 


\section{Perceptual significances of teacher evaluators}

Many of the teacher evaluators showed statistically similar judgments towards the errors. However, there were execution of some statistically significant differences found in the rating of the learner errors for younger and older native English evaluators, graduate and post-graduate native English evaluators, native and Nepali English evaluators, native English evaluators and non-Nepali evaluators, old Nepali evaluators, graduate and post-graduate evaluators, and trained and untrained non-Nepali evaluators. Nevertheless, as regards to the significance of mean scores, there were mixed outcomes revealed as well.

\section{Consensus built-up by different evaluators}

Arriving at a common meeting point is just quite unimaginable. When meeting of the minds of the three teacher evaluators Nepali, non-Nepali and native English in a place is a question, it is still very complicated and tough. The different teacher evaluators' meetings of minds on the chief grammatical categories are as follows:

\section{Meeting of minds among Nepali, non- Nepali and native English evaluators}

The three teacher evaluators, Nepali, non-Nepali and native English speakers, have reached at a common consensus in both acceptability and intelligibility judgments in the categories below:

Acceptability judgment: 'modal verbs $>$ relative clauses $>$ conjunctions $>$ interrogation $>$ reported speech $>$ tag questions $>$ conditionals $>$ articles' (On the basis of most serious to least serious)

Intelligibility judgment: 'relative pronouns > $\mathrm{S}-\mathrm{V}$ agreement $>$ relative clauses $>$ conjunctions $>$ prepositions $>$ tag questions $>$ reported speech' (On the basis of most serious to least serious)

Out of the eight common categories built up by the three groups of evaluators above, modal verbs followed by relative clauses ranked the most serious in order of gravity, and articles and conditionals as the least serious categories in the acceptability judgment. Similarly, relative pronouns and S-V agreement labelled the gravest and reported speech and tag questions the least serious categories in the intelligibility judgment.

\section{Meeting of minds among native English evaluators}

The five groups of native English evaluators showed common consensus of opinion in the rank order of gravity in acceptability and intelligibility judgments in the following categories:

Acceptability judgment: 'prepositions > passivization $>$ tag questions $>$ conjunctions $>$ reported speech $>$ relative pronouns $>$ to infinitive/ gerund forms'

Intelligibility judgment: 'negativization $>\mathrm{S}-\mathrm{V}$ agreement $>$ conditionals $>$ modal verbs $>$ reported speech $>$ relative clauses $>$ tense $>$ to infinitive/ gerund forms $>$ relative pronouns'

They ranked prepositions and passivization ahead of all in terms of their order of gravity and to infinitive and gerund forms and relative pronouns in the acceptability judgment. Likewise, in the intelligibility judgment, negativization and $\mathrm{S}-\mathrm{V}$ agreement ranked the gravest and relative pronouns and to infinitive and gerund forms the least grave categories.

\section{Meeting of minds among Nepali English evaluators}

The Nepali English teacher evaluators and their sub-groups had their common consensus of rank order of gravity in acceptability and intelligibility judgments in the following categories:

Acceptability judgment: ' $\mathrm{S}-\mathrm{V}$ agreement $>$ tense $>$ modal verbs $>$ relative clauses $>$ relative pronouns $>$ prepositions $>$ reported speech $>$ passivization $>$ tag questions'

Intelligibility judgment: 'negativization > relative pronouns $>$ articles $>\mathrm{S}-\mathrm{V}$ agreement $>$ tense $>$ conditionals $>$ prepositions $>$ relative clauses $>$ conjunctions $>$ reported speech' 
The different groups of Nepali English teacher evaluators have given $\mathrm{S}-\mathrm{V}$ agreement and tense the highest rank order of gravity in the acceptability judgment, but negativization and relative pronouns received the most severity in the intelligibility judgment. Likewise, tag questions and passivization, and reported speech and conjunctions have been labelled the least grave categories in the acceptability and the intelligibility judgments, respectively.

\section{Meeting of minds among non-Nepali English evaluators}

The non-Nepali English teacher evaluators and their sub-groups had their common consensus of rank order of gravity as follows:

Acceptability judgment: 'relative pronouns > negativization $>$ interrogation $>$ prepositions $>\mathrm{S}-\mathrm{V}$ agreement $>$ modal verbs $>$ passivization'

Intelligibility judgment: 'relative pronouns $>$ negativization $>$ interrogation $>$ conditionals $>$ prepositions $>$ modal verbs $>$ tag questions $>$ relative clauses $>$ reported speech $>$ tense $>$ articles'

Unlike the above different teacher evaluators, the non-Nepali English teacher evaluators have ranked very consistently the categories relative pronouns, negativization and interrogation on the top in terms of the order of gravity in both acceptability and intelligibility judgments. They have labelled passivization and articles in the lowest order of gravity in the acceptability and the intelligibility judgments, respectively.

The above categories of grammar where different evaluators tried to arrive at a meeting point state that the rank order of the native English and nonnative English evaluators do not correlate closely. The category which is very serious for one group is not equally serious for the other.

\section{Development of error hierarchy by different evaluators}

The native English and their sub-groups of evaluators have in overall developed a common hierarchy of the grammatical categories in acceptability and intelligibility judgments. They have rated negativization and $S$-V agreement the most serious and reported speech and relative clauses the least in the acceptability judgment. Likewise, in the intelligibility judgment, interrogation and relative pronouns have been rated the most serious and relative clauses and reported speech the least.

The Nepali English teachers and their sub-groups of evaluators have in both judgments rated negativization the most serious category, followed by $\mathrm{S}-\mathrm{V}$ agreement in acceptability judgment and relative pronouns in intelligibility judgment, respectively. Likewise, they have rated reported speech and relative clauses the least serious categories in the acceptability and relative clauses and modal verbs in the intelligibility judgments, respectively.

The non-Nepali English teacher evaluators have rated negativization and $\mathrm{S}-\mathrm{V}$ agreement the most serious categories and reported speech and relative clauses the least in the acceptability judgment. Similarly, relative pronouns and to infinitive and gerund forms, and reported speech and relative clauses have been rated the most serious and the least serious categories respectively in the intelligibility judgment.

The above hierarchies developed by different teacher evaluators prove that establishing universal hierarchies is difficult. An item tends to become very serious for one evaluator whereas it does not seem to be so for the other. The native English evaluators, Nepali and non-Nepali evaluators have individually developed hierarchies of error gravity; that is, they do not consider all errors to be equally serious. But more important, the present study might give an indication, of which errors are most irritating to them, a finding which we can use to bring our own error- evaluation practices in line with those of native and non-native teachers.

\section{Conclusion}

Out of various uses of English, our concern is with its use in Nepal for academic purposes which have led us to survive along with a chaotic situation. Our students' expectation has been unexpectedly overwhelming. Therefore, it has been most urgent 
that we all become very serious with our formal use of English. This paper then suggests for what we all can do so as to bring awareness in performance of English in the students in Nepal.

Written errors are much influenced by the factors such as nationality, age, gender, training and education. Therefore, when we evaluate learner errors, observation should be made to see in which situation and variability the examinee was in. It has also to be borne in mind that some errors are much irritable to native English teachers. The errors which are most irritating for the native English speaking teachers are the most serious errors for Nepali and non-Nepali English teachers as well. Such areas have to be explored separately and dealt with so as the learners may not commit them again. Moreover, evaluation schemes have to be developed and we should concentrate on those areas and treat them seriously.

Dr. Laxmi Bahadur Maharian is a Reader in English education
at the Department of English Education, Tribhuvan University,
Nepal. Dr. Maharian has mixed experiences of teaching
from Intermediate to Masters level. He has recently finished
his doctoral study entitled "A Study on Teachers' Perceptions
Towards the English Language Errors" from Faculty of
Education, Tribhuvan University, Nepal. He has already
contributed to NELTA as an executive member. His areas of
academic interest are English phonetics and writing. Half a
dozen books and a number of articles are credited to his
account.

\section{References}

Awasthi, J. R. (1995). A linguistic analysis of errors committed by Nepali learners of English. Unpublished doctoral dissertation, University of Hyderabad - India.

Davies, E. E. (1983). Error evaluation: the important viewpoint. ELT Journal, 37:4, $304-311$.

Ervin, G. L. (1979). Communication strategies employed by American students of Russian. Modern Language Journal, Vol. 63 No 7, 329-34.
Flatley, J. (1997). Identifying and rating learner error in ELT: A comparison of native speaker and non-native speaker teachers in terms of judging acceptability attitudes to error and treatment of error. Unpublished MA Dissertation, English Language Institute, University of Surrey.

Hughes, A. \& Lascaratou, C. (1982). Competing criteria for error gravity. ELT Journal, 36/3, 175-82.

James, C. (1977). Judgments of error gravity. ELT Journal. 31:2, 116-124.

James, C. (1998). Errors in language learning and use: exploring error analysis. Longman, London.

Kamhi-Stein, L. D. (2000). Non-native English-speaking professionals: A new agenda for a new millennium. MEXTESOL Journal, 233, 11-20.

Kobayashi, T. (1992). Native and nonnative reactions to ESL compositions. TESOL Quarterly, Vol. 26, No. 1 Spring, pp. 81-112.

McCretton, E. \& Rider, N. (1993). Error gravity and error hierarchies. IRAL, 31/3: 177-88.

Perpignan, H. (2003). Exploring the written feedback dialogue: a research, learning and teaching practice. Language Teaching Research, 7 (2): 259-78.

Saidian, S. (2002): Identification and production of English articles by Iranian EFL students. An unpublished MA (TEFL) thesis. Tehran, Iran.

Santos, T. (1988). Professors' reactions to the academic writing of non-native speaking students. TESOL Quarterly, Vol 22 No 1, 69-90.

Schmitt, N. (1993). Comparing native and non-native teachers' evaluation of error seriousness. Japanese Association of Language Teachers: Journal, Vol. 15, No 2, 181 - 9.

Sheorey, R. (1986). Error perceptions of native speaking and non-native speaking teachers of ESL. ELT Journal, 40.4, 306-310.

Shi, L. (2001). Native and non-native speaking EFL teachers' evaluation of Chinese students' English writing. Language Testing, Vol. 18, No. 3, PP 303-325 23 


\section{APPENDIX I}

\section{GENERAL TEST ITEMS FOR STUDENTS}

\section{A. MULTIPLE CHOICETESTS}

\section{(I). Read the following questions and tick $(\checkmark)$ the best answer.}

NOTE: 'o' refers to 'No article'.

They have developed the village as ......tourist trade.
(a) a
(b) an
(c) the
(d) $\mathrm{o}$

He ...... the driver to leave his rucksack on the seat.
(a) ask
(b) has been asked
(c) had asked
(d) asked

3. ......you mind not telling anyone?
(a) Should
(b) Would
(c) Will
(d) Could

Frank decided ......up karate.
(a) to take
(b) taking
(c) take
(d) to taking

People ...... me something to eat now and again.
(a) gave
(b) would have given
(c) give
(d) will be giving

$\mathrm{He}$ waterproof clothing while sailing.
(a) takes
(b) has taken
(c) may take
(d) has been taking

The house is on ......main road.
(a) an
(b) a
(c) the
(d) 0

He ...... all morning.
(a) is walking
(b) was walking
(c) will walk
(d) is walks

The toast ...... badly because he wasn't watching.
(a) is burning
(b) burnt
(c) was burning
(d) has burnt

I ...... engineering while I was at university.
(a) study
(b) studied
(c) was studying
(d) would study

\section{(B). SHORT ANSWER QUESTIONS}

(II) Read the situations below and write the answers in a sentence OR two OR as instructed:

1. You have just won Rs. 80000o/- on the football pools.

Decide what to do with the money. Write your answers using the structures below:

\begin{tabular}{|l|l|l|}
\hline I think I'll... & I don't think I'll... & I'm going to.... \\
\hline
\end{tabular}

i.

ii.

iii.

2. Someone keeps tapping his/her foot.

Now make a couple of polite questions using the sentence patterns in the box. 
Do you think you could..................? - I'm trying to write an essay.

Would you mind not ......................? - I'm trying to write an essay.

3. You have a guest for the weekend.

What do you say if he looks thirsty? Write a couple of sentences using the structures in the box.

\begin{tabular}{|l|l|}
\hline Shall I ..................(for you)? & Would you like to...............? \\
\hline
\end{tabular}

i.

ii.

\section{(C). ESSAY TYPE QUESTIONS}

(III). Read the following questions and write the answers in not more than 100 words.

1. Describe the arrangement of rooms and other features in your house or flat

Ans:

Write a paragraph on 'beggars'. Use in your description the attitudes - such as surprising irritating embarrassing exciting depressing annoying etc.

Ans:

Describe the village or town you are living in.

Ans:

Give a description of a person's face general appearance clothes life style and habits etc.

Ans:

Write a couple of sentences about your favourite activities and dislikes.

Ans:

\section{APPENDIX II}

\section{ERROR EVALUATION QUESTIONNAIRE}

Name:

Sex: Male / Female-

Age:

Qualification:

Training: (trained/untrained):

Profession:

Experience: (in years)

Origin (Nationality):

Native language: 


\section{Dear sir/madam}

Please read the following sentences recorded from the writings of the higher secondary school level students of Nepal and evaluate them on the basis of your perception of their acceptability and intelligibility. Please follow the five-way distinction given below and write 1, 2, 3, 4 or 5 whichever you think is sensible in the box against each sentence.

\section{Acceptability}

1. Perfectly acceptable

2. Highly acceptable

3. Acceptable

4. May be acceptable

5. $\quad$ Not acceptable at all

\section{Intelligibility}

1. Perfectly intelligible

2. Highly intelligible

3. Intelligible

4. May be intelligible

5. Not Intelligible at all

Note: Please, give your reading of intelligibility in the first box and that of acceptability in the second box. Write 1 if the sentence you think is perfectly acceptable/intelligible, 2 for highly acceptable/intelligible, 3 for acceptable/intelligible, 4 for may be acceptable/intelligible and if you think it is not acceptable/intelligible at all, write 5 .

For your kind information, it is tried to define acceptability as 'the degree to which a given piece of interlanguage is tolerated by the speakers of the target language' and intelligibility as 'the degree to which an intended message can be understood'.

PART 'A'

\begin{tabular}{|c|l|c|c|}
\hline S.No & \multicolumn{1}{|c|}{ Grammatical Items for Evaluation } & \multicolumn{2}{c|}{ Criterion for Evaluation } \\
\cline { 2 - 4 } & & Acceptability & Intelligibility \\
\hline 1. & You should take the umbrella in this rainy season. & & \\
\hline 2. & l'm not sure if I'll recognize Aunt Emily when I will meet her at the air- & & \\
\hline 3. & Robert has bought an old house, which was in a terrible condition. & & \\
\hline 4. & She has been working harder ever since she has got her pay rise. & & \\
\hline 5. & & & \\
\hline 6. & The firm may make a profit if they attracted new customers. & & \\
\hline 7. & If he has been more careful, he would get very good marks. & & \\
\hline 8. & All of them knows how to read. & & \\
\hline 9. & In spite of her parents objected, she still insisted on getting married. & & \\
\hline 10. & It's two days when I last had a meal. & & \\
\hline 11. & Because of his scruffy appearance, he got the job. & \\
\hline 12. & When does he start playing the guitar. & & \\
\hline 13. & Could you know how much that hi-fi costs? & \\
\hline 14. & How long ago have you become a teacher? & \\
\hline 15. & She isn't in the office; she might be having coffee in the canteen. & \\
\hline
\end{tabular}

